\title{
A Comparative Study of b- and d-Waves of the Electroretinogram, in Frogs (Rana Catesbeiana)
}

\author{
S. MOLOTCHNIKOFF, AND F.GUERTIN-LAURIN
}

SUMMARY: The aim of this study was to compare the $b$-and d-waves of the ERG. evoked respectively by $O N$ and $O F F$ stimuli. The experiements were carried out on frogs. The d-wave is facilitated by light adaptation and relatively high stimulus intensity. The depth profiles of $b$ - and $d$ waves are different. Aspartic acid abolish-

RESUME: Le but du présent travail est de comparer les ondes $b$ et d de l'ERG. évoquées respectivement par les stimuli $O N$ et $O F F$. Les expériences furent effectuées sur des grenouilles. L'apparition de l'onde dest facilitée par l'adaptation à la lumière et par l'intensité de stimulation relativement élevée. L'exploration laminaire intra-rétinienne a montré que les

From the Département de Sciences biologiques Université de Montréal.

Reprint requests to: Dr. S. Molotchnikoff, Département de Sciences biologiques, Université de Montréal, C.P. 6128, Succursale "A", Montreal H3C 3J7 Canada ed only the b-wave whereas nembutal affected the $d$-wave. These results suggest$e d$ that $b$ - and $d$-waves were produced by separate neuronal mechanisms, even though both appeared as positive deflection in the corneal ERG and were sensitive to $K^{+}$ion.

ondes b et $d$ ont un profil distinct. Enfin l'acide aspartique abolit seulement l'onde b alors que le nembutal agit surtout sur l'onde $d$. Les résultats montrent que les ondes $b$ et d sont issues de mécanismes nerveux distincts même si les deux apparaissent comme des déflections positives à l'ERG cornéen et sont sensibles aux ions $K^{+}$.

\section{INTRODUCTION}

All light stimulation has two symmetrical components: the $O N$ stimulation and its opposite, the OFF stimulation. Each of these excites the retina and the activity can be measured by an electroretinogram (E.R.G.). An analysis of the components of the E.R.G. reveals that $\mathrm{ON}$ stimulation evokes three well established components: the $\mathrm{a}, \mathrm{b}$ and $\mathrm{c}$ waves corresponding respectively to the $\mathrm{P}$ III, $\mathrm{P}$ II, and $P$ I processes described by Granit (1933). These components are found in all vertebrate species. The E.R.G. components evoked by the OFF stimulation have been more or less neglected and are not well understood (Skoog et al., 1977). In 1935, Granit observed that retinae could be divided into two classes, depending on the species. Type I retinae presented large OFF responses while type E produced only weak OFF responses. Several hypotheses have been advanced to explain the origin of the rather complex OFF response. For example, the work of Noell (1953) and Faber (1969) on rabbits, Crescitelli and
Sickel (1968) on frogs, and Skoog et al. (1977) on humans have shown that the OFF response contains delayed OFF components. Fast components with a peak time of less than $500 \mathrm{msec}$ are also present. Among the fast components, the d-wave which appears as a positive deflection in the corneal E.R.G. is the most prominent. Little is known about the origin of the $d$-wave and the mechanisms of its formation. Brown (1968) suggested the $d$-wave results from decay of the cone potential followed by decay of a D.C. (direct-coupled) component. Knaves et al. (1972) and Knave and Persson (1974) proposed that the OFF response results from the summation of decays of two D.C. potentials of inverse polarity. More recently, Miller (1973) has postulated that the d-wave produced by OFF stimulations and the $b$-wave evoked by $O N$ stimulation are both sensitive to potassium ions and therefore have a similar electrophysiological origin. However, Miller (1973) suggested that it does not necessarily follow that the two waves arise from a single population of cells.

To shed some light on the formation of the retinal OFF response, this study attempted to draw a parallel between the b- and d-waves in the frog E.R.G., using various conditions of photic stimulation, retinal exploration, and the application of pharmacologic agents.

\section{METHOD}

\section{Animal preparation}

Frogs (Rana catesbeiana) obtained from a local supplier were kept in a tank with room-temperature water flowing continuously. They were all kept in darkness for at least 24 hours prior to the experiment. The animals 
were decerebrated and their eyes extirpated under a dim red light. The cornea, iris and lens were removed and the vitreous humour was absorbed by tissue paper. A residual layer of vitreous was left in place as a precaution against pulling at the retina which could have resulted in its tearing. This residue was estimated to be from 100-200 micron thick, depending on the preparation. This thickness was deducted from the micromanipulator index between the disappearance of 60 c.p.s. (indicating contact) and the recording of the first action potentials from the ganglion layer. The eye cup thus obtained was kept in a plexiglas chamber to immobilize it. Forty-five experiments were performed. The retina was maintained at room temperature $\left(22^{\circ} \mathrm{C}\right)$ throughout the experiment.

\section{Simulation and recording}

From a lamp (Sylvania K300), two optic fibers conducted a light beam above the retina $(3.5 \mathrm{~cm})$. One of these provided ambient light; the second was used as a test flash. The unattenuated intensity was estimated to be 70 Lumen $/ \mathrm{m}^{2}$ for each beam; this corresponded to an intensity of $0 \mathrm{log}$ units (U.L.). Neutral filters (Wratten Kodak) were placed on the light beams to reduce their intensity. Except where specifically indicated, the intensity of the adapting light and test flash were established at I U.L. and 2.5 U.L. respectively, above threshold $(40 \mu \mathrm{V})$. ON and OFF stimulation were provided by opening and closing an electromagnetic shutter. The stimulus duration was $1 \mathrm{sec}$ and the flashes were applied every $30 \mathrm{sec}$ except in the experiment on light adaptation.

Two types of retinal recordings were made. The E.R.G. was recorded by means of an electrode, made of a small cotton wick attached to an $\mathrm{Ag} / \mathrm{AgCl}$ wire placed on the retinal surface. A local E.R.G. was recorded through a tungsten microelectrode insulated except at its tip with Insl-X. The retinal signals were then conveyed via a preamplifier (R.M. 122 Tektronix, pass band: $8-250 \mathrm{~Hz}$ ) and to a memory oscilloscope from which they were photographed for later analysis.
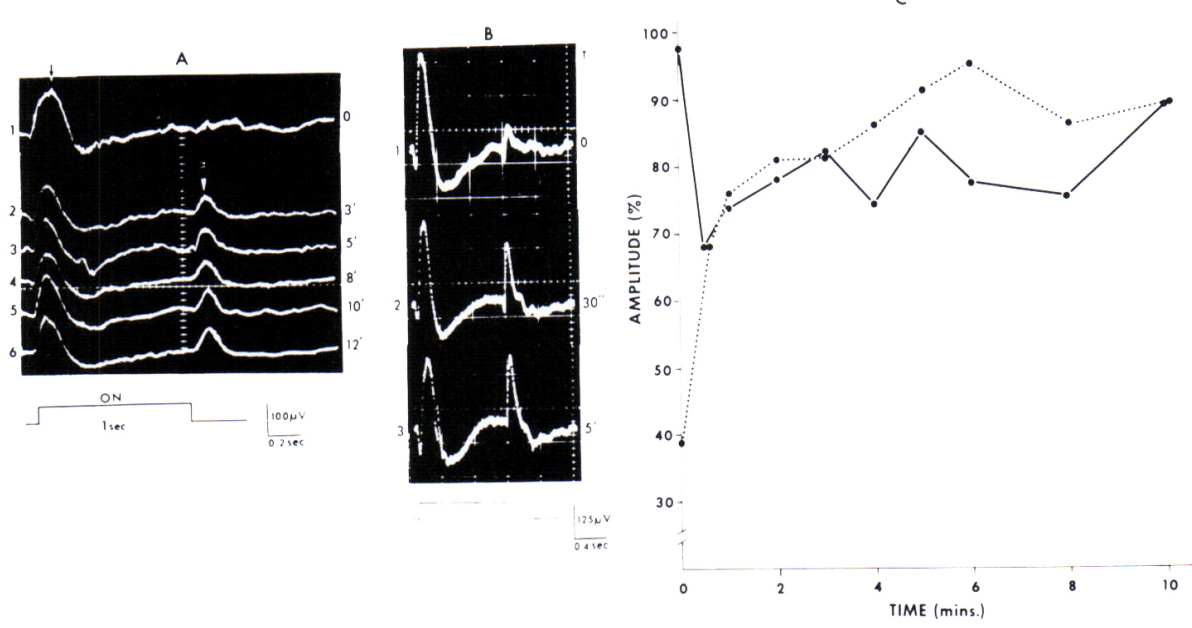

Figure 1-The effect of light adaptation upon the b-and d- waves of the ERG. In A trace I: local ERG obtained in dark. Black arrow points to the b-wave (Note the absence of the d-wave). Trace 2: ERG obtained $3 \mathrm{mn}$ after adapting light was turned $O N$. Note the appearance of the d-wave (white arrow). Numbers to the right indicate time in minutes after the adapting light was turned $O N$. In B: same as in A but responses were obtained following the averaging of 8 consecutive presentations. The first presentation in trace 2 occurred $30 \mathrm{sec}$ after the adapting light was turned ON. In C: Amplitude of b- and dwaves plotted as a function of time during light adaptation. Data from each experiment were normalized. Solid line: b-wave; dotted line: d-wave. Amplitudes were measured from the base line to the peak of the wave, in this and all subsequent figures. Lowest traces in $\mathrm{A}$ and $\mathrm{B}$ indicate the light stimulation: upward deflection is for $\mathrm{ON}$ steps and downward deflection is for OFF steps.

\section{RESULTS}

1) Photic conditions

\section{a) Light adaptation}

The b-wave of the E.R.G. was easily obtained when a light flash of sufficient intensity was presented. However, to obtain the OFF response, certain experimental conditions were necessary.

First, because the b-wave was ample and presented a relatively slow time course (250-300 msec), it was desirable that the duration of the flash be longer than this to permit the appearance of an OFF response uncontaminated by the b-wave. As had been found in many previous studies, the d-wave of the OFF response increased almost linearly with the light period preceding the OFF stimulation (Guertin-Laurin, 1977). The second condition was much more important since it suggested that the d-wave was specific to the retinal photopic system. Even with a 1-sec flash, the OFF response only appeared if a weak adapting light was added (Fig. 1). Fig. 1A, B, C show that the dwave was more sensitive than the bwave to light adaptation. Thus, in darkness there was no OFF response (Fig. 1A, trace 1). The application of an adapting light whose intensity was 1 U.L. above threshold intensity $(40 \mu \mathrm{V})$ produced a typical d-wave (white arrow, Fig. 1A, trace 2) when the stimulation was of the OFF type. The peak time of this component was 150 msec. As the period of adaptation increased, the d-wave grew in amplitude while the b-wave (dark arrow) returned almost to its initial level $(130 \mu \mathrm{V})$ after a brief decrease at the beginning of adaptation. Fig. 1B shows the results of a similar experiment in which eight successive stimulations applied every 10 secs were averaged. Prior to adaptation (Fig. $1 \mathrm{~B}$, trace 1), a weak OFF response was evoked. It was composed of an initial negative deflection followed by the $d$ wave that peaked at $150 \mathrm{msec}$. Five minutes after adaptation, the d-wave reached a value that was almost the same as that of the b-wave (Fig. IB, trace 3 ) (260 and $230 \mu \mathrm{V}$ respectively). Furthermore, the d-wave was followed by a negative response. The presence of the d-wave prior to light adaptation (Fig. 1B, trace 1) can be attributed to 
the fact that with averaging procedures a repetition of the stimulus produces weak light adaptation.

The curves on Fig. 1C illustrate the change in the $b$-(solid line) and $d$ (dotted line)-waves during adaptation. The highest value corresponds to the maximum amplitude obtained. as soon as adaptation began, the relative amplitude of the b-wave decreased (30\%), then increased slightly and finally reached a plateau at $80 \%$ of its value recorded in the dark. The d-wave showed a different evolution. From its minimal value, it almost doubled in amplitude during the first 2 minutes of adaptation and then grew more slowly and reached its plateau in the sixth minute of adaptation. These results show that ambient illumination potentiates the appearance of the OFF response in its positive form: the dwave.

b) Variation in stimulation intensity

The potentiation of the $d$ component in photopic conditions suggests that this wave would show an enhanced amplitude at higher levels of stimulation. The experiments on the changes in the b- and d-waves during variation of light intensity showed that, although the d-wave increased in amplitude with brighter flashes, the increase was limited for intermediate intensities, since with higher intensities the d-wave showed a decline in amplitude. This is illustrated in Fig. 2; typical experiment is shown on the left side. At threshold (3.5 U.L., lowest trace), the b- and d-waves had an amplitude of 50 and $65 \mu \mathrm{V}$ respectively. With a change in light intensity from 3.5 to 0 U.L., the b-wave increased in amplitude, going from 50 to $180 \mu \mathrm{V}$. Between 3.5 and 2.0 U.L., the amplitude of the $d$-wave went from 65 to $180 \mu \mathrm{V}$, but above this intensity the $d$-wave decreased in magnitude to become barely perceptible when the stimulation light was at 0 U.L. (upper trace, Fig. 2). The curves of the Fig. 2 (right) show the different behavior of the b-and $d$ - waves as the stimulation intensity increased. The two potentials progressed in parallel in terms of amplitude for 3.0 to $1.5 \mathrm{U}$.L., but after 1.5 U.L. the d-wave decreased while the b-wave continued to grow in
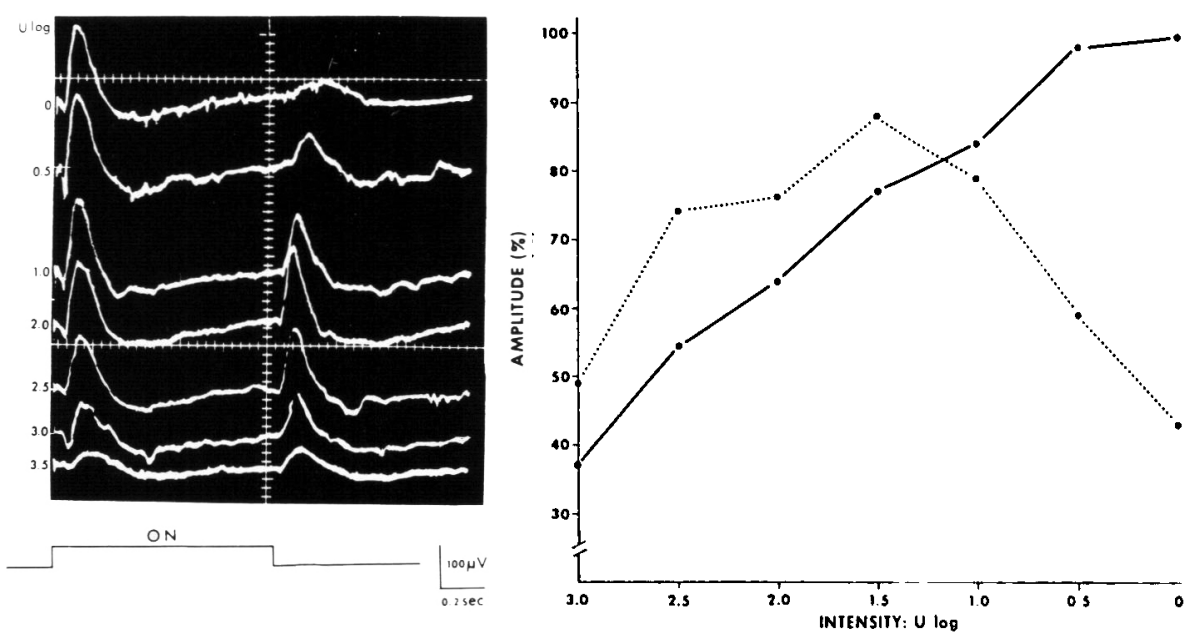

Figure 2-Effect of varying stimulus intensity on the local ERG. Left column: example of responses to increasing intensities which are indicated to the left in log units (the highest intensity being equal to $0 \log$ units, that is unattenuated light). Note at the four lower intensities from 3.5 to $2.0 \mu \mathrm{L}$ the $\mathrm{d}$-wave increases in magnitude and then declines as the intensity increases further. Right column: Amplitude of b-and d-waves plotted as a function of light intensity. Data from each experiment were normalized. Continuous curve: b-wave; dotted curve: d-wave.
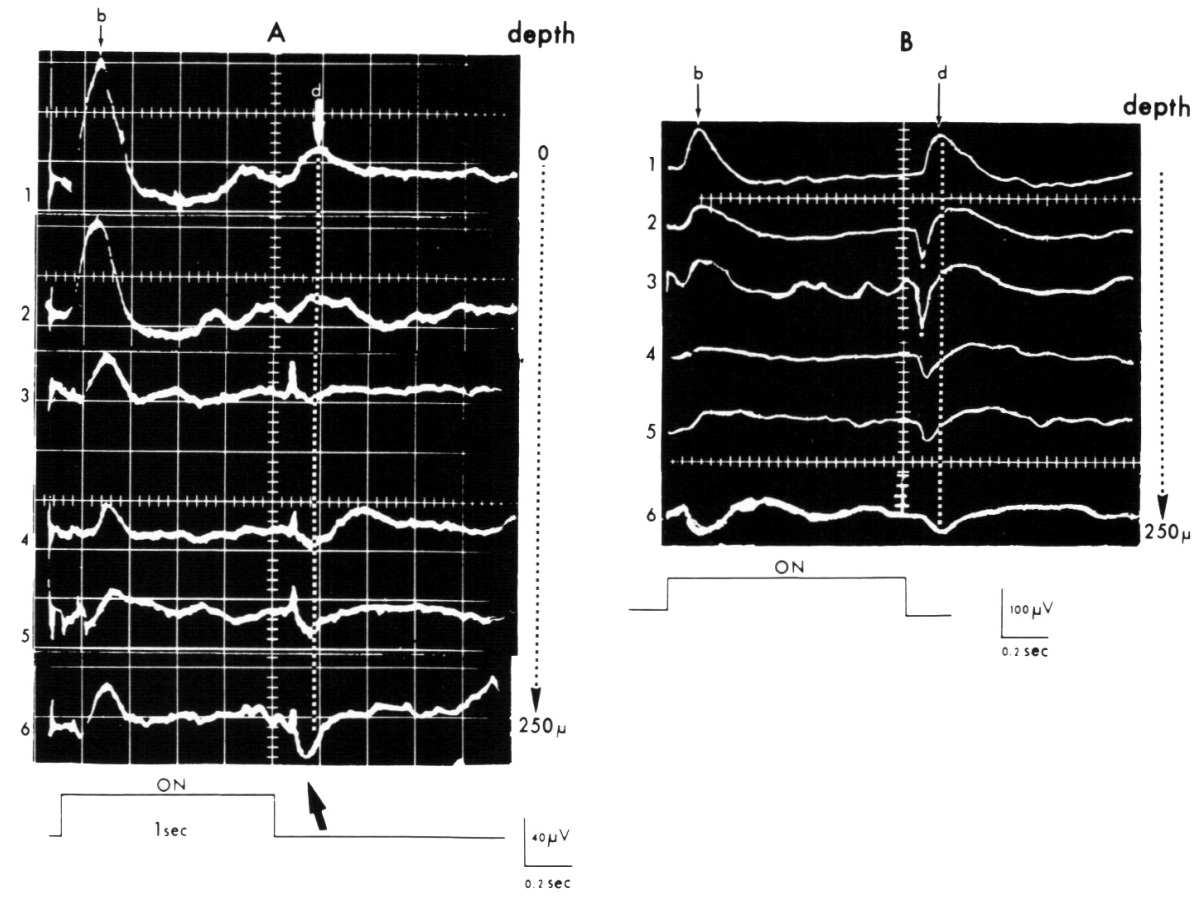

Figure 3-Local ERG recorded as a function of electrode depth. Two different retinae one for each column. Surface of the vitreous (contact) indicated by 0 . In B: white dots point to the presumed Proximal Negative Response. The dotted lines indicate the peak of the d-wave as recorded superficially.

amplitude and attained a plateau at 0.5 U.L.

\section{2) Retinal depth profile}

Intralaminal exploration serves two purposes: it can reveal the sources and sinks of the b- and d-waves and, in passing through the different layers of the retina, it is possible to record evoked responses from cells in each layer in response to $O N$ and $O F F$ stimulation. Fig. $3 A$ and $B$ show that the $d$-wave reversed its polarity sooner 
than did the b-wave. In Fig. 3, trace 1, the $b$-and $d$-waves were both positive $(110 \mu \mathrm{V}, 30 \mu \mathrm{V})$. The electrode was on the vitreous side and had just made contact. The b-wave had an amplitude of $35 \mu \mathrm{V}$ and remained positive 225 microns deeper (Fig. 3A, trace 6). At 150 microns after contact, the OFF response showed an early component of positive polarity with a latency of 90 msec. This component probably originated from amacrine cell activity (Ogden and Wylie, 1970; Burkhardt, 1970) (Fig. 3A, traces 3-6). At this 'depth, the d-wave was small but its polarity had already reversed. Advancing the electrode tip further toward the external retinal layers made it possible to record negative $d$ waves of increasing amplitude. It reached $40 \mu \mathrm{V}$ at 225 microns following contact; in this experiment, the b-wave remained positive (Fig. 3A, trace 6). Another example is illustrated in Fig. 3B. Again, the dwave reversed before the $b$-wave when the electrode penetrated the retina in a vitreous-receptor direction. Furthermore, Fig. 3B shows that in the internal retinal layers the $d$-wave was preceeded by a faster potential of opposite polarity with a peak time of $90-100$ msec (Fig. 3B, traces 2, 3, white dot). The failure of polarity reversal during a retinal penetration, together with its occurrence at proximal layers, suggested that this component belonged to proximal negative response (Burkhardt, 1970). Because of the addition of this potential, OFF stimulation gave rise to a positive response with a peak time between 100 and $150 \mathrm{msec}$, intermediate between the d-wave and the early negative component. However, as the electrode moved farther away from the site of origin of this early wave its influence decreased and the OFF response contained only the typical reversed $d$ component with a peak time of 150 $160 \mathrm{msec}$.

These results showed that the $b$ and d deflections have their sources and sinks located at different depth within the retina. Intralaminar exploration also showed that the d-wave could be preceded by a negative potential if recordings were made from the vitreous side.

\section{3) b-and d-wave sensitivity modified by aspartic acid and barbiturates}

a) Effects of aspartic acid

The results of the preceding procedure demonstrated that the band $\mathrm{d}$ - waves originated at different levels of the retina. Applying aspartic acid can provide a more exact determination of the distinct origins of the two waves. This drug selectively abolishes electrophysiological response from the internal layers of the retina. Cervetto and $\mathrm{McNichol}$ (1972) showed that only the receptors responded when the retina was treated with aspartic acid. Fig. 4A shows the effect of aspartic acid on the b-and dwaves. Prior to the application of one drop of the acid (25 $\mathrm{mM}$ applied to the surface of the retina), the b- and dwaves had amplitudes of $1250 \mu \mathrm{V}$ and $500 \mu \mathrm{V}$ respectively. One minute after application, the $b$-wave diminished to $800 \mu \mathrm{V}$ while the $\mathrm{d}$-wave remained unchanged (Fig. 4A, trace 2). As the drug's effects increased, the b-wave decreased in amplitude and almost disappeared 25 mins after the start of the test (Fig. 4A, trace 5). The disappearance of the b-wave permitted the recording of a long negative potential whose initial decay is the a-wave of the E.R.G. (trace 5 white pointer).

In contrast, the d-wave was never abolished. It had an amplitude of 400$500 \mu \mathrm{V}$ during the 25 -minute period of application of the acid. The latency of its positive going deflection remained constant but the negative decay was much less abrupt (Fig. 4A, traces 3, 4, $\& 5)$. At time $t=0$ (trace 1$)$, the return to baseline occurred in $400 \mathrm{msec}$. After 5 minutes of acid application, the time to return to baseline doubled: 800 msec (trace 3). The decrease in amplitude of the d-wave can be attributed to the prominence of the negative potential forming the a-wave. Similarly, the slow return of the awave could have lengthened the decay time of the d-wave. These results indicate that, unlike the b-wave, the dwave is insensitive to sodium aspartate and therefore, originates in the external retinal layers.

\section{b) Effects of barbiturate}

Eccles et al. (1963), Knave and Parson (1974), Noell (1958), Yonemura et al. (1966), and Nicoll (1978) showed that sodium pentobarbital acts by inhibiting synaptic transmission. Fig. 4B illustrates the effects of this drug on the b-and d-waves. The E. R.G. was recorded at the cornea and the drug was injected into the vitreous humour $(0.1 \mathrm{cc}, 6 \mathrm{mg})$. Before injection, the b- and d-waves had amplitudes of $1400 \mu \mathrm{V}$ and $450 \mu \mathrm{V}$ respectively. Immediately after the injection, both waves showed an increase in amplitude (b: $1650 \mu \mathrm{V}$ and d: $700 \mu \mathrm{V}$; Fig. 4B, trace 2), suggesting that the slight increase in intraocular pressure following the injection did not depress the amplitudes. After the fifth post-injection minute, a decrease in amplitude occurred (traces 4-6). Thus, the b-wave reached $700 \mu \mathrm{V} 35$ minutes after the injection while the $d$ wave was selectively abolished during this period. These results suggest that since the b-wave is secondary to neuronal activation from distal to internal layers of the retina (Miller and Dowling, 1970; Cervetto and MacNichol, 1972), there also might be a process of transcellular communication prior to the formation of the $d$ wave. As shown above, the d-wave is insensitive to sodium aspertate and therefore arises from the external layers of the retina. It is likely that the communication takes place at this level. It is also noteworthy that selectively inhibiting the $d$-wave reveals the presence of a negative deflection with a peak time of about 200 msecs and a time course (Fig. 4B, trace 6) which is similar to that of the typical d-wave.

\section{DISCUSSION}

This comparison of $b-$ and d-waves has shown that: 1) the appearance of the d-wave is facilitated by the presence of an adapting light; 2) the depth profile is distinct for each of these waves and 3 ) their sensitivity to aspartic acid and barbiturates is different. The results suggest that the $b$-and d-waves do not reflect activity in the same population of retinal cells even though they are both produced by Muller cell depolarization (Miller and Dowling, 1970; Miller, 1973; Karkowski and Proenza, 1977).

Fig. 5 summarizes the various components involved in the formation of the corneal OFF response. Only the 

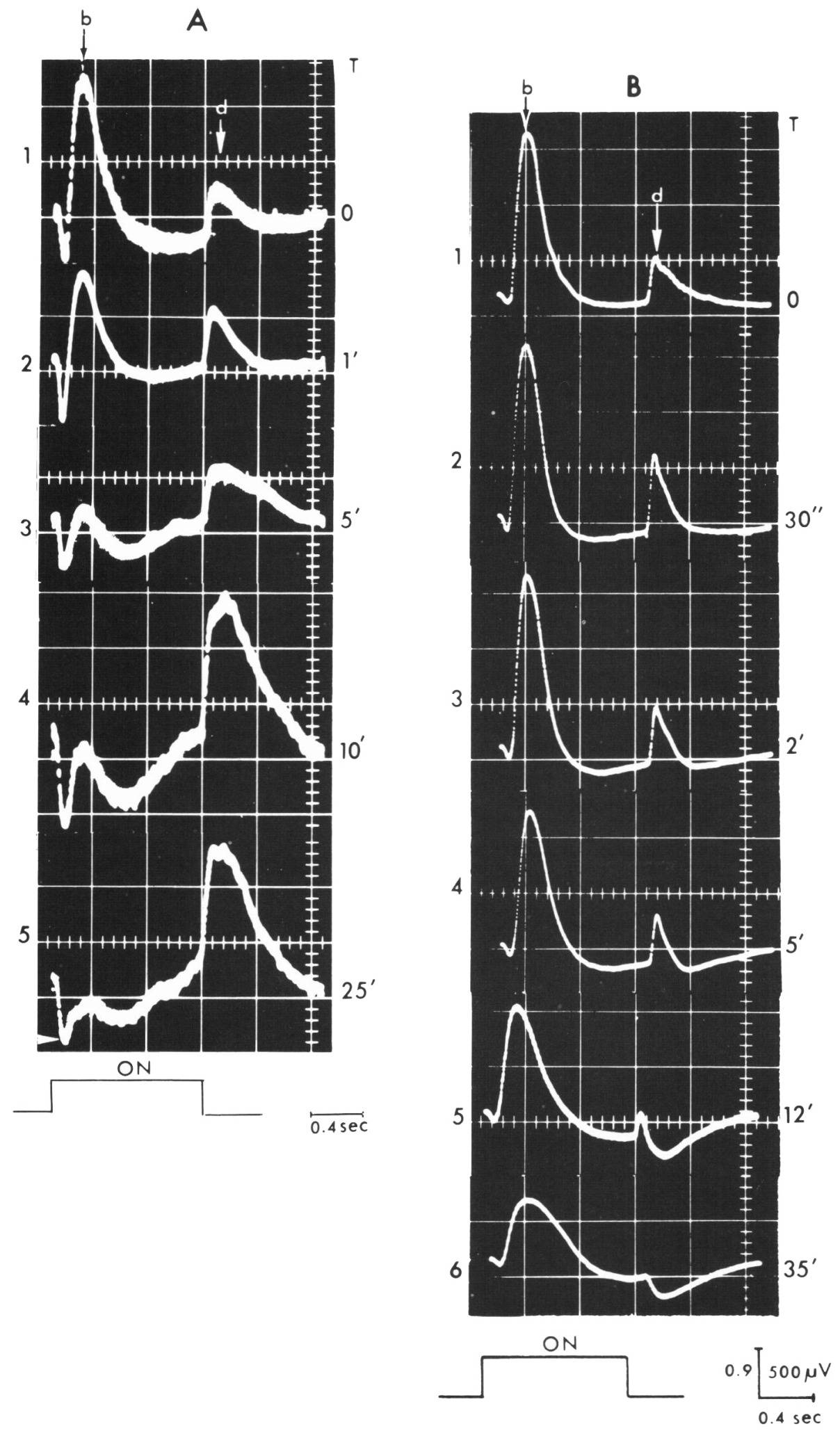

Figure 4-b- and d-waves sensitivity to aspartic acid in A and nembutal in B. In A: decline of the b-wave whereas the d-wave is relatively unaffected. In B: decline of the d-wave whereas the $b$-wave persists. The disappearance of the $d$-wave reveals a negative potential. Numbers to the right of each column indicate the time after the drug was applied. T: Time. Vertical calibration $500 \mu \mathrm{V}$ in all traces except in A traces 4 and 5: $200 \mu \mathrm{V}$. fast and transient components are considered. The longer latency components following the $d$ component, such as the $\mathrm{c}, \mathrm{g}$ and h-waves (Skoog et al., 1977) will not be discussed.

The corneal OFF response seems to have three major neural components (Fig. 5). The earliest component is negative, fastrising and transient and it is mainly apparent at the proximal retinal level (Fig. 5, trace 1). These characteristics suggest that this component is related to the proximal negative response (P.N.R.) observed by Burkhardt (1970) in frogs and Proenza and Freeman (1977) in the Necturus. It might arise from the activity of amacrine cells. The second component is also negative but peaks much later than the P.N.R. wave; it is generally masked by the d-wave whose temporal course is similar but of opposite polarity. Its presence was evident by the selective abolition of the d-wave by barbiturates (Fig. 4B). The following hypothesis may explain the formation of this negative wave. It might be formed by the algebraic summation of the depolarizing deflection of receptors and by a return of a positive d.c. potential (Brown, 1968) both produced by the OFF stimulus. In humans, it has been called the fwave (Skoog, 1977). In the rabbits (Laffond et al., 1977) and cats (Brown, 1968) a negative wave has been observed immediately following the dwave. Furthermore, in rabbits it increases in amplitude and thereby decreases the amplitude of the d-wave at high levels of stimulation (Laffond et al., 1977). This is analogous to the decrease in the d-wave amplitude observed in frogs after presentation of high levels of intensity of stimulation (Fig. 2).

Finally, the third component, the most prominent, is the $d$-wave. It is of interest because it has important characteristics that are relevant to clinical application.

Some of its properties are related to the functioning of the photopic retinal system. It is facilitated by the presentation of an adapting light and high intensity flashes. Its insensitivity to sodium aspartate suggests that the cellular elements underlying its 

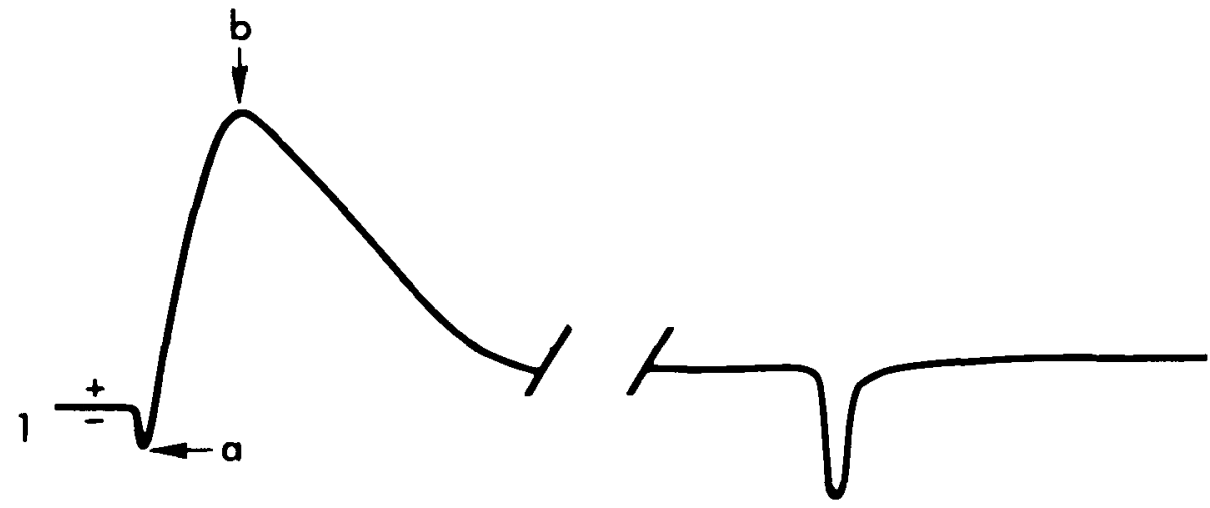

2

3
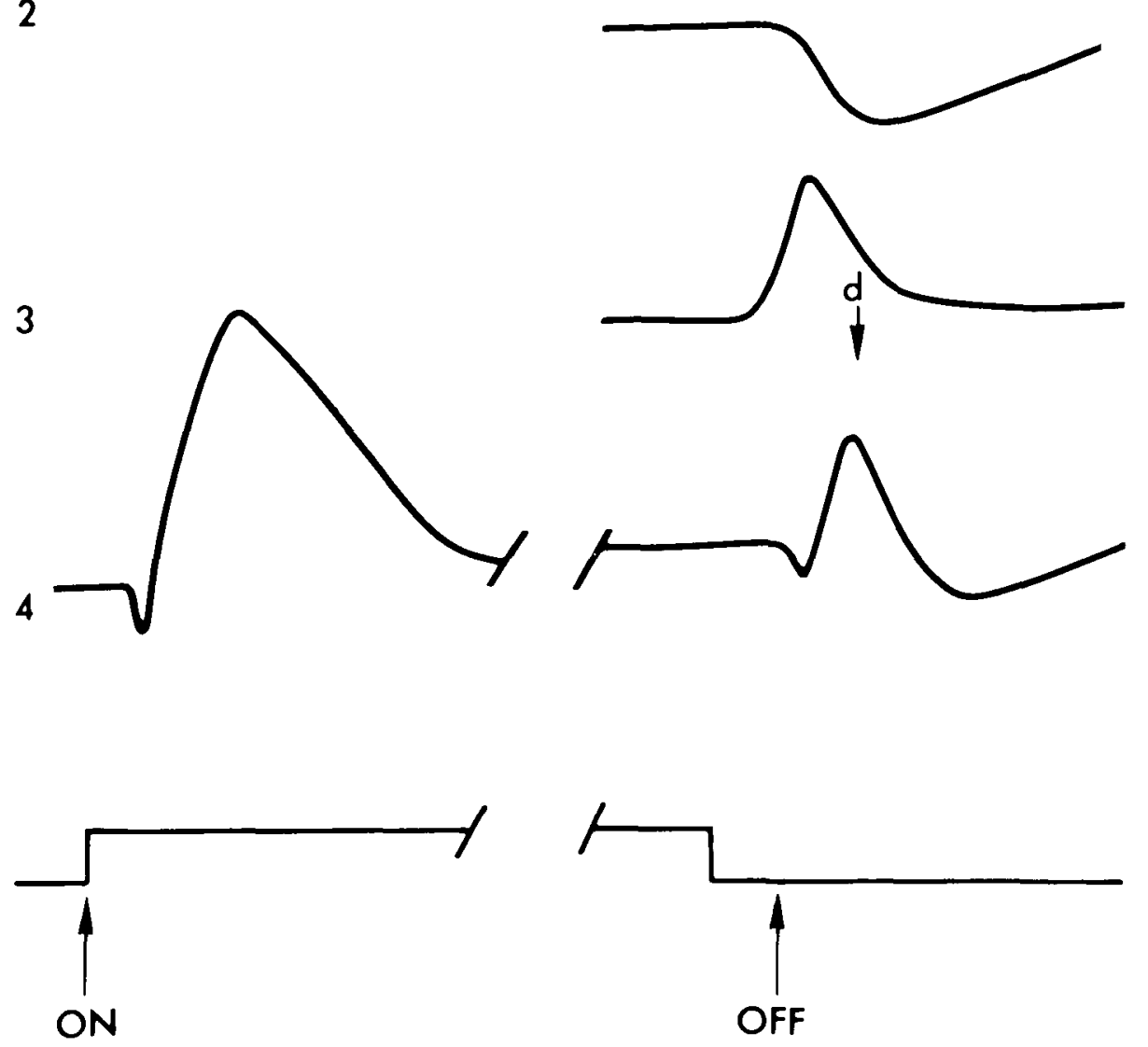

(Stimulus : 1 sec.)

Figure 5-Schematic component analysis of light adapted frog's ERG. Conventional recording is assumed, with active electrode in front of the retina and the reference electrode behind the eyes. For purpose of illustration and clarity the a- and b-waves are broader than normal and are omitted in traces 2 and 3. ONLY the components evoked by the OFF stimulus are analysed. Trace 1 depicts the negative potential observed in the proximal layer. It has been associated to the Proximal Negative Response (Fig. 3-B); Trace 2 illustrates the negative potential revealed by nembutal application which abolishes the d-wave (Fig. 4-B); Trace 3: positive deflection, i.e. the d-wave. Trace 4: The complex OFF response is made from a simple algebraic sum of these three major neural components. formation are located distally and are probably receptors (Cervetto, 1972). Because of its potentiation by photopic conditions, it is possible that it is produced by the action of cones. The possibility of relating the $d$-wave to cone activity was further confirmed by a rapid survey of corneal retinal responses in many different species. In lampreys (Holmberg, 1977), frogs (Tomita, 1960), turtles (Armington, 1974), squirrels (Arden and Tansley, 1955), and pigeons (Ogden and Wylie, 1971) OFF stimulation produces a positive corneal response associated with cone activity, while animals with predominantly rod retinae show only a low amplitude or negative OFF response (Granit, 1935; Brown, 1968).

The duality of the OFF response that is either positive or negative depending on whether the response arises from the photopic or scotopic system has important clincial implications since the E.R.G. is used as a diagnostic tool to evaluate retinal pathology. The presence of a prominent b-wave dominating the other E.R.G. components make the OFF response, a more discriminatory index of retinal functions.

\section{ACKNOWLEDGEMENTS}

We are most grateful to Mrs. A. Laperrière and D. Lorazo for their secretarial assistance. This research was supported by NRCC (A6943), Université de Montréal, and D.G.E.S. du ministère de l'Education du Québec, and C.R.S. du Québec (730023).

\section{REFERENCES}

ARDEN, G. B. and TANSLEY, K. (1955). The spectral sensitivity of the purecone retina of the grey squirrel (Sciurus carotinensis leucotis). Journal of Physiology (Lond.) 127: 592-602

ARGMINGTON, J. C. (1974). The electroretinogram. Academic Press, New York.

BROWN, K. T. (1968). The electroretinogram: its components and their origins Vision Research, 8: 633-677.

BURKHARDT, D. W. (1970). Proximal negative response of Frog retina. Journal of Neurophysiology, 33: 405-420.

CER VETTO, L. and MacNICHOL, E. F. (1972). Inactivation of horizontal cells in Turtle retina by glutamate and aspartate. Science, 178: 767-768.

CER VETTO, L. and PICCOLINO, M. Synaptic transmission between photoreceptors and horizontal cells in Turtle retina. Science 183: 417-418. 
CRESCITELLI. F. and SICKEL. W. (1968) Delayed OFF-responses recorded from isolated frog retina. Vision Research 8: 801-816.

ECCLES. J. C. (1946). Synaptic potentials of motor neurones. Journal of Neurophysiology, 9: 87-119.

FABER, D. S. (1969). Analysis of the slow transretinal potentials in response to light. Thesis, State University of New York at Buffalo.

GRANIT, R. (1935). Two types of retinae and their electrical responses to intermittent stimuli in light and dark adaptation. Journal of Physiology, (London), 85: 421-438.

GRANIT, R. (1933). The components of the retinal action potentials in mammals and their relation to the discharge in the optic nerve. Journal of Physiology, (London), 77; 207-239.

GUERTIN-LAURIN, F. (1977). Parallèle entre les ondes b et $d$ de l'ERG évoquées par les stimulations photiques $O N$ et OFF. Thèse M.Sc. Université de Montréal.

HOLNBERG, K., OHMAN, P. and DREYFERT. T. (1977). ERG recordings from the retina of the river Lamprey (Lampetra Fluviatilis). Vision Research 17: 715-717.
KARKOWSKI, C. J. and PROENZA, L. M. (1977). Relationship between Muller cell responses, a local transretinal potential and potassium flux. Journal of Neurophysiology 40: $244-259$

KNAVE, B. and PERSSON, H. E. (1974). The effect of barbiturate on retinal functions. I. Effects on the conventional electroretinogram of the sheep eye. Acta Physiologica. Scandinavica, 91: 53-60.

KNAVE, B., MOLLER, B. A. and PERSSON, H. E. (1972). A component of the electroretinogram. Vision Research, 12: 1669-1684.

LAFFOND, G., BRUNETTE, J. R. and MOLOTCHNIKOFF, S. (1977). Etude de la réponse "OFF" cornéenne dans l'oeil intact du lapin. Canadian Journal of Ophthalmology, 12: 41-46.

MILLER, R. F. (1973). Role of $\mathrm{K}^{+}$in generation of b-wave of electroretinogram. Journal of Neurophysiology 36:28-38.

MILLER, R. F. and DOWLING, J. E. (1970). Intracellular response of the Muller (Glial) cells of mudpuppy retina: Their relation to bwaves of the electroretinogram. Journal of Neurophysiology, 33: 323-341.
NICOLL, R. A. (1978). Pentobarbital: Differential post synaptic actions on sympathetic ganglion cells. Science, 199: 451-452.

NOELL, W. K. (1953). Studies on the electrophysiology and metabolism of the retina. U.S.A.F. School of Aviation Medicine, Randolph Field, Texas.

NOELL, W. K. (1958). Differentiation, metabolic organization and viability of the visual cell. Archives of Ophthalmology, 60: 702733.

OGDEN, T. E., WYLIE, R. (197I). Avian retina. I. Microelectrode depth and marking studies of local ERG. Journal of Neurophysiology, 34: 357-366.

PROENZA, L. M. and FREEMAN, J. A. (1971). Light evoked extracellular potentials of the necturus retina: current source density analysis of the electroretinographic b-wave and the proximal negative response. Neuroscience Abstract, 1: 104.

SKOOG, K. O., WELINDER, E. and NILSSON, S. E. G. (1977). Responses in the human D.C. registered electroretinogram. Vision Research, 17: 409-415.

TOMITA, T. MURAKAMI, and HASHIMOTO, I. (1960). On the R-membrane in the frog's eye, its localisation and relation to the retinal action potential. Journal of General Physiology, 43: 81-98. 